\title{
CRESCIMENTO ANORMAL DO GRÃO AUSTENÍTICO E SUA INFLUÊNCIA NA FRAÇÃO VOLUMÉTRICA DE AUSTENITA RETIDA APÓS A TÊMPERA DE UM AÇO ABNT 5 I35
}

\author{
Camila de Brito Ferreira ' \\ Paulo José Modenesi ${ }^{2}$ \\ Dagoberto Brandão Santos ${ }^{2}$
}

\section{Resumo}

O tamanho de grão nos aços é bastante importante nos tratamentos térmicos de têmpera. A temperatura e tempo de austenitização maiores levam ao aumento dos grãos austeníticos. Por sua vez, após a têmpera de um aço baixa liga, a microestrutura é constituída por martensita e uma fração de austenita retida, dependente de vários fatores, inclusive do tamanho de grão austenítico. Neste trabalho, estudou-se a influência do tamanho de grão austenítico sobre a fração volumétrica de austenita retida, após a têmpera de um aço ABNT 5I35. Foram medidas as áreas dos grãos da austenita bem como a quantificação de austenita retida por difração de raios- $X$. As temperaturas de $M_{i}$ e $M_{f}$ foram determinadas por equação empírica e experimentalmente por análise térmica diferencial. Também foram feitos testes de microdureza Vickers. Foi mostrado que o aumento do grão austenítico promove uma maior fração volumétrica de austenita retida após a têmpera em água, diferentemente do que é relatado na literatura, quando se comenta que a temperabilidade do aço aumenta com o tamanho de grão austenítico.

Palavras-chave: Austenita retida; Grão austenítico; Têmpera; Crescimento de grão.

\section{INFLUENCE OF ABNORMAL AUSTENITE GRAIN GRAIN GROWTH IN QUENCHED ABNT 5 I 35 STEEL}

\begin{abstract}
Grain size in the steels is a relevant aspect in quenching and tempering heat treatments. It is known that high austenitizing temperature and long time provide an increase in austenitic grain sizes. Likewise, after hardening of low alloy steel, the microstructure consists of martensite and a volume fraction of retained austenite. This paper evaluates the influence of austenite grain size on the volume fraction of retained austenite measured by metallographic analyses and $X$-ray diffraction. The $M_{i}$ and $M_{f}$ temperatures were calculated using an empirical equation and experimentally determined by differential thermal analysis. The mechanical behavior of the steel was evaluated by Vickers microhardness testing. Differently from other results published in the literature that steel hardenability increases with the austenite grain size, it was observed that the increase in austenite grain promotes greater volume fraction of retained austenite after water quenching.

Keywords: Martensite; Retained austenite; Athermal martensite; Grain growth.
\end{abstract}

\section{INTRODUÇÃO}

No processo de têmpera o aço sofre a transformação da austenita para martensita, e, eventualmente, outros constituintes como ferrita, perlita e bainita. A transformação inicia-se a uma temperatura $M_{i}$, e é necessário alcançar a temperatura $M_{f}$ para sua finalização. Geralmente, a transformação não é completa, pois à medida que as placas ou ripas de martensita se formam durante o resfriamento elas circundam e isolam pequenas áreas de austenita, que recebe a denominação de austenita retida; a qual poderá ser transformada para martensita por resfriamento sub-zero ou no revenimento subsequente [1-3]. Frequentemente, a austenita retida é indesejável, pois degrada as propriedades mecânicas do aço temperado, leva a alterações dimensionais, diminuição em sua dureza, redução da tenacidade e do

'Escola de Engenharia, Universidade Federal de Minas Gerais - UFMG, Belo Horizonte, MG, Brasil.

${ }^{2}$ Departamento de Engenharia Metalúrgica e de Materiais, Escola de Engenharia, Universidade Federal de Minas Gerais - UFMG, Belo Horizonte, MG, Brasil.E-mail: dsantos@demet.ufmg.br. 
limite de resistência à fadiga [4,5] Em outras situações, esta pode até ser benéfica, pois proporciona uma maior ductilidade da peça temperada após cementação $[4,6]$. Independentemente de sua influência, a sua quantificação é fundamental quando se avalia o desempenho mecânico dos aços temperados $[1,4,6]$.

Vários trabalhos foram relatados ao longo dos anos sobre a dependência da temperatura $M_{i}$ em relação ao tamanho de grão da austenita; incluindo pesquisas recentes que envolvem a formação de estruturas com grãos ultrafinos e nanométricos [7-10]. A temperatura de austenitização também afeta $M_{i}[8,9]$, mas através da variação associada ao tamanho de grão austenítico [9].

As placas de martensita crescem de forma rápida, sendo a cinética da transformação controlada por sucessivos eventos de nucleação $[10, I I]$. Várias explicações qualitativas sobre a influência do tamanho de grão da austenita na formação da martensita têm sido propostas. Um dos argumentos é que o refinamento do grão da austenita provoca o aumento de sua resistência mecânica pelo efeito Hall-Petch, tornando-se assim mais difícil a formação da martensita [ 1 ]. Sabe-se que 0 aumento da resistência por solução sólida afeta a nucleação da martensita devido a uma maior resistência ao movimento das discordâncias envolvidas no processo de nucleação na austenita [8]. Por outro lado, a relação de Hall-Petch baseia-se na transmissão de deslizamento de discordâncias através dos contornos de grão, enquanto, em função da natureza displaciva da transformação, a martensita em si não pode continuar no grão vizinho [I I]; desse modo a resistência ao movimento de discordâncias na fase de nucleação tem que ser mais localizada. De fato, as equações para o volume de ativação no movimento termicamente ativado da interface martensita/austenita referem-se apenas ao volume varrido pela interface entre o núcleo e a fase matriz [8].

Os contornos de grãos da austenita constituem um ambiente favorável à formação de embriões de martensita [ I I]. Assim, quanto menor o tamanho de grão mais locais para a nucleação estariam disponíveis. Por outro lado, os núcleos devem crescer até que atinjam o contorno de grão oposto. Como este crescimento se dá pelo cisalhamento da rede da austenita, esta também deve passar por uma etapa de acomodação das deformações, sendo então necesário um maior superresfriamento para a continuidade da transformação, ou seja, menor $M_{i}[3,8,9, I I] O$ oposto ocorre nos aços alto carbono e com granulação grossa da austenita. Uma fração de martensita é formada e, em seguida, acontece o fenômeno de explosão, em que uma grande fração da austenita se transforma em martensita dentro de um intervalo de temperatura muito pequeno [1 I-13]. A tendência para uma explosão ocorrer diminui à medida que o tamanho de grão da austenita é refinado [12]. Isto é explicado qualitativamente pelo fato de que a concentração de tensões na ponta de uma placa de martensita varia com o tamanho da mesma, que por sua vez está relacionado com o tamanho de grão da austenita. A transformação ocorre em uma temperatura mais alta para os grãos austeníticos maiores [9]. Um modelo geométrico de particionamento do grão austenítico foi proposto inicialmente por Fisher et al. [14] e utilizado por Guimarães e Rios [10] para descrever a formação da martensita de forma quantitativa. Segundo os autores, a transformação martensítica é controlada pela nucleação e, na maioria das ligas ferrosas, exibe uma cinética atérmica. Assim, as unidades de martensita dividem os grãos de austenita. Na sequência, as novas unidades formam-se em tais partições, e assim por diante. Como consequência, o volume médio da placa é reduzido.

Se por um lado vários trabalhos abordam a influência do tamanho de grão da austenita e sua composição química sobre a temperatura $M_{i}$ e sua cinética [15-17], poucas referências mencionam o efeito deste parâmetro sobre a fração de austenita retida $[4,18]$. Quando se menciona o efeito da granulação mista da austenita ou aquela originada do crescimento anormal de grão, nenhuma referência foi encontrada na literatura. Nessa direção, foram objetivos deste trabalho: i) avaliar a influência da temperatura e tempo de austenitização no tamanho do grão austenítico e a relação deste com a fração volumétrica de austenita retida em um aço ABNT 5/35 temperado em água; ii) determinar os valores de $M_{i}$ e $M_{f}$ a partir da analise térmica diferencial do perfil de temperatura obtido experimentalmente durante a têmpera de amostra deste aço; e iii) correlacionar estas informações para avaliar a variação da fração volumétrica de austenita retida com o tamanho de grão austenítico prévio.

\section{MATERIAL E MÉTODOS}

Neste trabalho foi utilizado um aço comercial ABNT 5 I35, cuja composição é listada na Tabela I.

As amostras do aço foram austenitizadas em sete temperaturas: $800^{\circ} \mathrm{C}, 850^{\circ} \mathrm{C}, 900^{\circ} \mathrm{C}, 950^{\circ} \mathrm{C}, 1.000^{\circ} \mathrm{C}, 1.100^{\circ} \mathrm{C}$ e $1.200^{\circ} \mathrm{C}$ durante $15 \mathrm{~min}$ e depois temperadas em água com agitação à temperatura ambiente. Posteriormente, para avaliar o efeito do tempo de austenitização sobre tamanho do grão austenítico, realizou-se o encharque a $1.200^{\circ} \mathrm{C}$ por $2 \mathrm{~h}$, seguindo-se o mesmo procedimento de têmpera. As amostras para exames metalográficos foram preparadas de maneira convencional até o polimento final com pasta de diamante de I $\mu \mathrm{m}$. No ataque químico da superfície polida utilizou-se o reativo nital $2 \%$. A microestrutura foi registrada através da microscopia óptica e eletrônica de varredura. Para revelação e medição do tamanho do grão austenítico utilizou-se o reativo de solução saturada de ácido pícrico. O tamanho do grão austenítico foi determinado em microscópio óptico Leitz, usando do programa LAS3, por meio da medição da área de cada grão em micrografias armazenadas no próprio programa. Foram feitas medições até

Tabela I. Composição química do aço ABNT 3135\% peso

\begin{tabular}{ccccccc}
\hline Elemento & $\mathbf{C}$ & $\mathbf{M n}$ & $\mathbf{S i}$ & $\mathbf{P}$ & $\mathbf{A l}$ & $\mathbf{C r}$ \\
\hline Teor & 0,39 & 0,69 & 0,23 & 0,026 & 0,020 & 0,98 \\
\hline
\end{tabular}


se alcançar um erro relativo absoluto menor que $10 \%$. Para tanto, foram medidos no mínimo 200 grãos por amostra. Em algumas situações, quando ocorreu o crescimento anormal, foram medidos mais que 500 grãos por amostra. $O$ tamanho de grão listado nos resultados a seguir corresponde à raiz quadrada da área média obtida. Medidas de microdureza Vickers foram realizadas com carga de 2,9 N (300 gf) a fim de verificar a influência variação da fração volumétrica de austenita retida e ferrita no comportamento mecânico do aço temperado. A difratometria de raios- $X$ foi realizada à temperatura ambiente em um difratômetro Philips PW 1710. Para quantificação da fração volumétrica da austenita retida, pelo método de integração da área abaixo dos picos de difração, consideraram-se os picos: (III), (200), (220), (3II) da austenita e (II0), (200), (2II), (220) da ferrita. A integração das intensidades foi feita com o auxílio do software Origin ${ }^{\mathrm{TM}}$, seguindo a metodologia descrita em outro trabalho dos autores [19]. Para a determinação experimental das temperaturas de início e fim da mudança de fases no processo de têmpera, realizou-se a austenitização a $900^{\circ} \mathrm{C}$, seguida de têmpera em água. Em amostra com dimensões de $15 \mathrm{~mm}$ de diâmetro e $30 \mathrm{~mm}$ de altura fez-se um orifício de I,2 mm de diâmetro e inseriu-se um termopar tipo K no centro da mesma para registrar o perfil de temperatura. Com o auxilio de uma interface eletrônica $A / D$ foi feita a aquisição de dados de temperatura no aquecimento e resfriamento, a uma taxa de 20 medições/s durante todo o ciclo térmico. A partir desses dados, e a utilização do método das derivadas [20], determinou-se as temperaturas $M_{i}$ e $M_{f}$

\section{RESULTADOS E DISCUSSÃO}

\section{I Caracterização Metalográfica nas Diferentes Temperaturas e Tempos de Austenitização}

As Figuras la-Id ilustram micrografias ópticas de amostras austenitizadas a $800^{\circ} \mathrm{C}, 1.200^{\circ} \mathrm{C}$ e $1.200^{\circ} \mathrm{C} / 2 \mathrm{~h}$, após a têmpera. É possível perceber na Figura I que a microestrutura predominante é de martensita. $\mathrm{O}$ ataque com reativo de ácido pícrico seguido do reativo nital $2 \%$ visou uma melhor caracterização da microestrutura martensítica e do contorno de grão austenítico anterior. A Figura Id
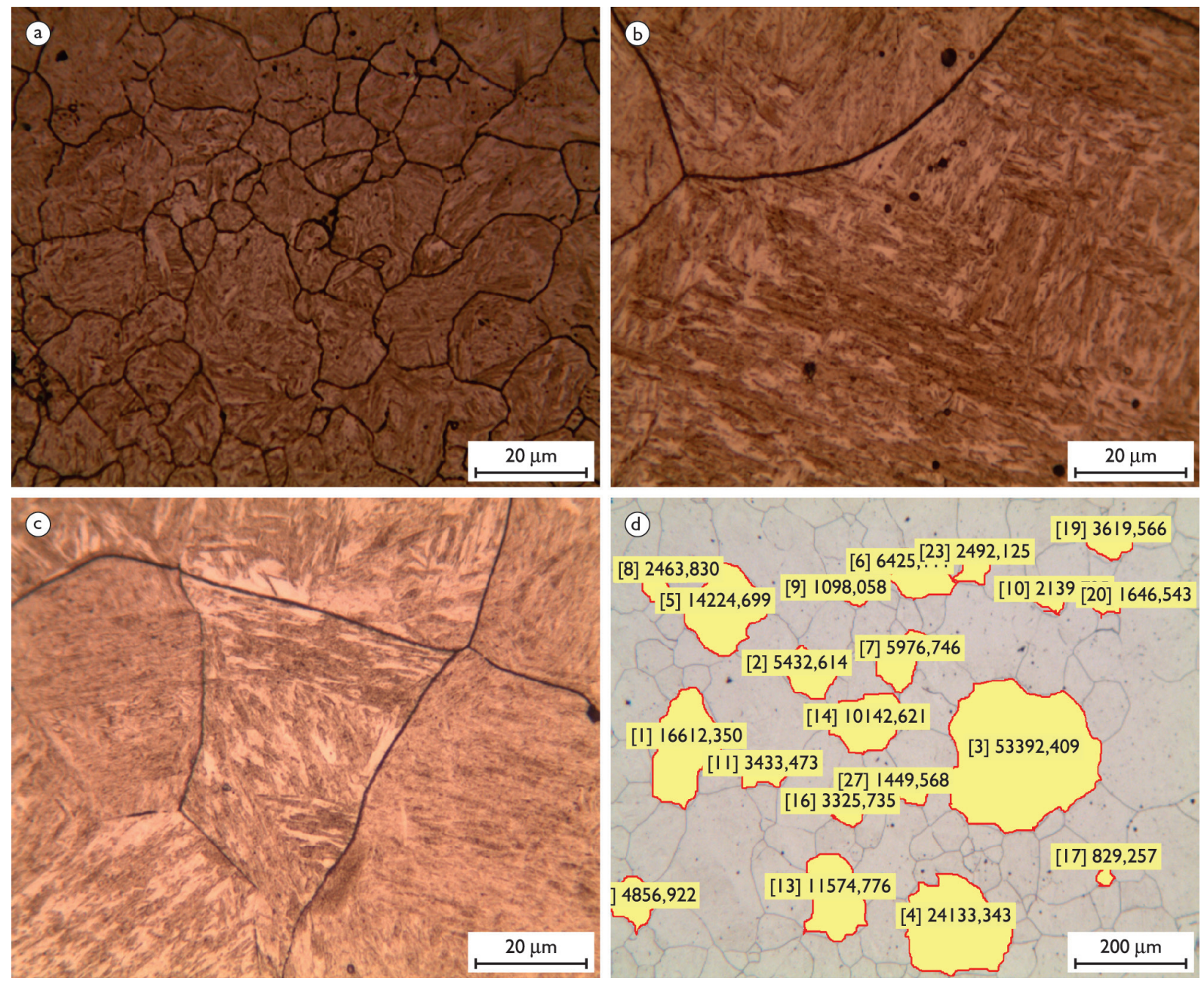

Figura I. Micrografias ópticas das amostras austenitizadas a: (a) $800^{\circ} \mathrm{C} / 15 \mathrm{~min}$, (b) $1.200^{\circ} \mathrm{C} / 15 \mathrm{~min}$ e (c) $1.200^{\circ} \mathrm{C} / \mathrm{I} 20 \mathrm{~min}$ e (d) ilustração do processo de medição do tamanho de grão austenítico. Ataque com reativo de ácido pícrico saturado e nital $2 \%$. 
exemplifica a forma como essas medidas foram realizadas para amostra de $1.200^{\circ} \mathrm{C} / 15 \mathrm{~min}$.

As Figuras $2 \mathrm{a}$ e $2 \mathrm{~b}$ ilustram as micrografias eletrônicas de varredura das amostras austenitizadas a $800^{\circ} \mathrm{C}$ e I. $200^{\circ} \mathrm{C}$. Ao se analisar a Figura 2 percebe-se uma matriz predominantemente martensítica nas amostras, não sendo possível identificar, através das mesmas, a presença de austenita retida, que de acordo com a literatura se apresenta na forma de filmes entre as placas de martensita $[1,4]$. Regiões de ferrita proeutetóide são indicadas por setas nas micrografias (Figuras 2a e 2b). É nítida a variação dimensional das ripas de martensita; estas aumentam de tamanho com o aumento da temperatura de tratamento (Figuras $2 \mathrm{a}$ e 2b). Nas Figuras $3 a$ e 3 b evidencia-se a ocorrência de crescimento anormal de grão da austenita prévia.

A Figura 4 ilustra a variação do tamanho do grão austenítico com a temperatura e o tempo de austenitização. O aumento da temperatura de austenitização promove um significativo aumento do tamanho de grão austenítico. A partir de $1.100^{\circ} \mathrm{C}$ inicia-se um crescimento anormal dos grãos, sendo este estabilizado à temperatura de $1.200^{\circ} \mathrm{C}$. Com o aumento do tempo de austenitização para $2 \mathrm{~h}$ a $1.200^{\circ} \mathrm{C}$ não há uma variação perceptível no tamanho médio do grão austenítico em relação à amostra tratada na mesma temperatura por 15 min. Ocorre, contudo, uma mudança na distribuição do tamanho de grão, a qual se torna mais homogênea.

\subsection{Análise Quantitativa da Fração Volumétrica da Austenita Retida nas Diferentes Temperaturas e Tempos de Austenitização}

Os difratogramas apresentados na Figura 5 são para amostras austenitizadas a $800^{\circ} \mathrm{C}$ e $1.200^{\circ} \mathrm{C}$. Observa-se na Figura 5 a presença predominantemente de martensita, o que era esperado, considerando a microestrutura ilustrada
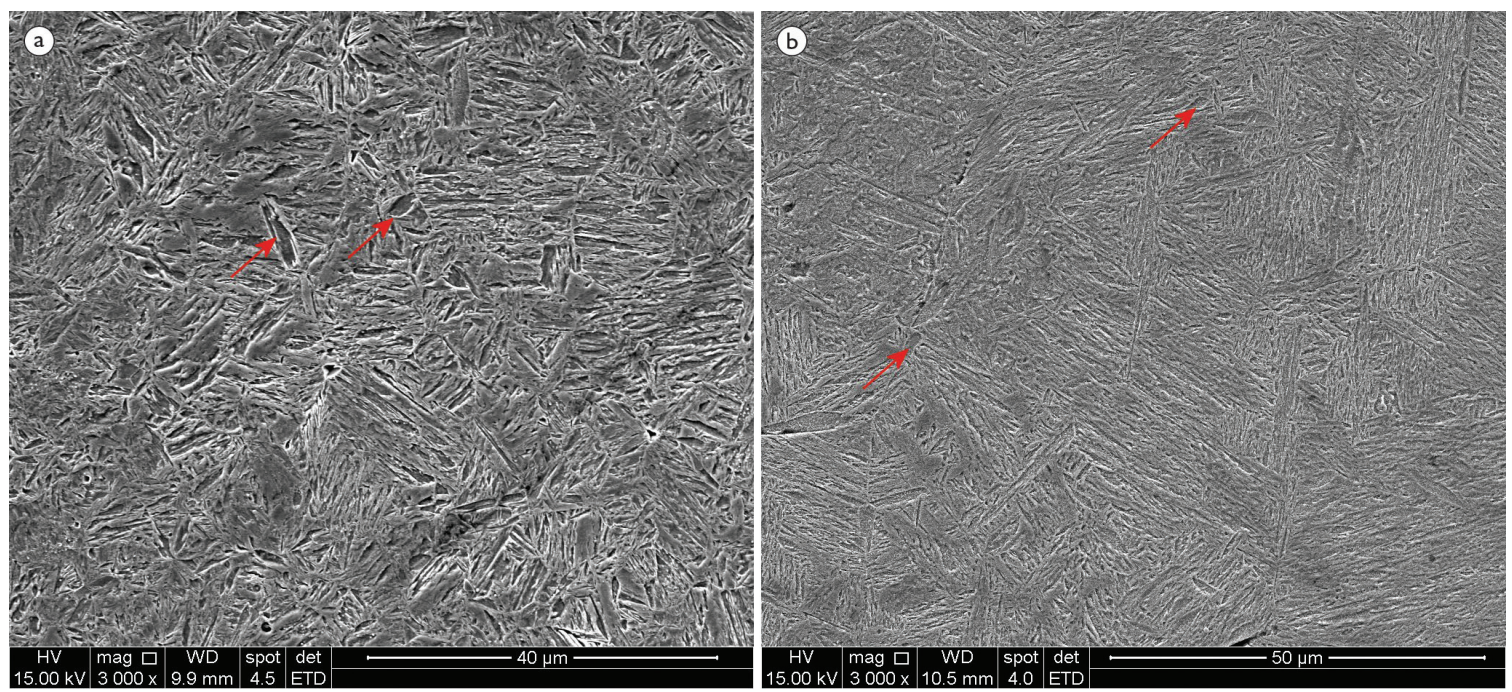

Figura 2. Micrografias eletrônicas de varredura das amostras após têmpera em água a (a) $800^{\circ} \mathrm{C}$; (b) $1.200^{\circ} \mathrm{C} / 2 \mathrm{~h}$. Ataque com reativo nital $2 \%$.
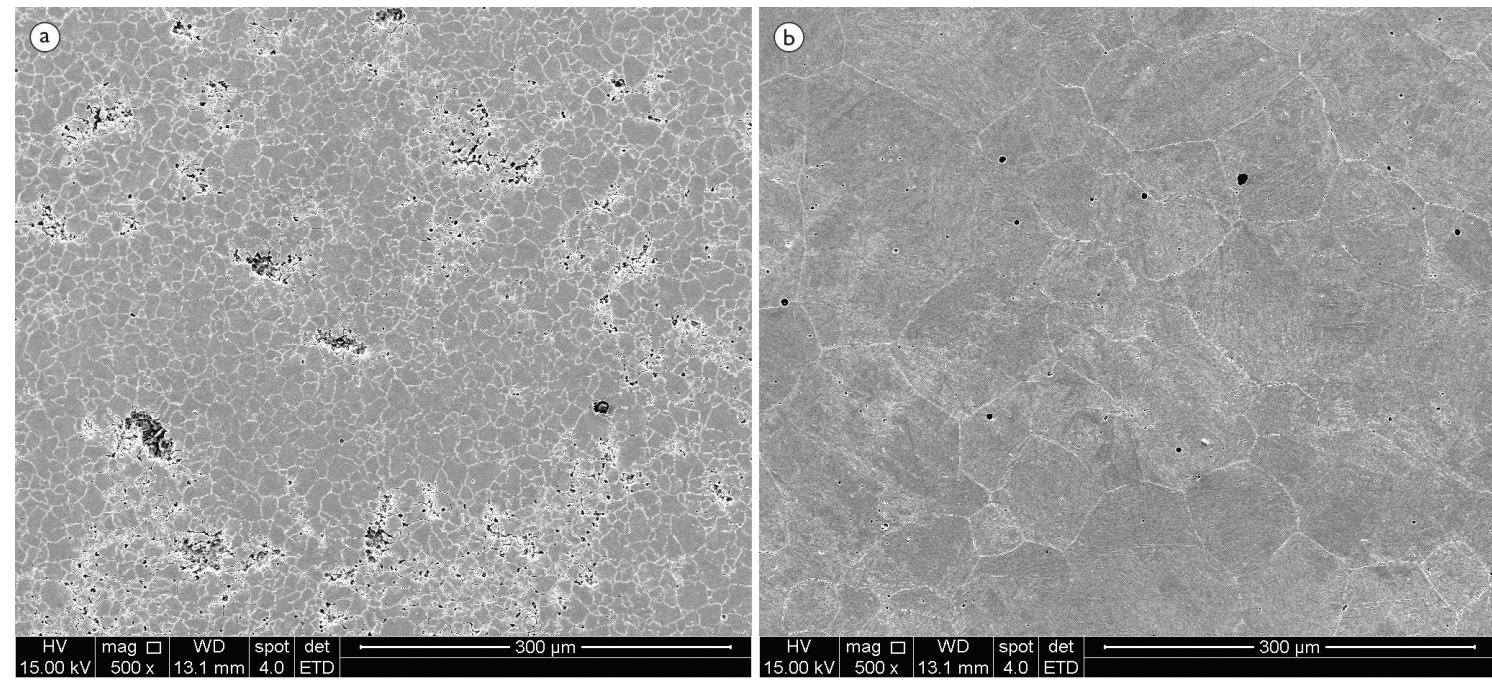

Figura 3. Micrografias obtidas no MEV das amostras austenitizadas a (a) $800^{\circ} \mathrm{C} \mathrm{e} \mathrm{(b)} 1.200^{\circ} \mathrm{C}$. Ataque com reativo de ácido pícrico. 
nas Figuras I a 3. A austenita é identificada no difratograma da amostra austenitizada a $1.200^{\circ} \mathrm{C}$ e pode ser percebida, com alguma dificuldade, na amostra de $800^{\circ} \mathrm{C}$, ambas com 15 min de encharque. Na Figura 6 estão plotados os valores de microdureza em função da temperatura de austenitização. A variação da quantidade de austenita em relação à temperatura de austenitização de $800^{\circ} \mathrm{C}$ a $1.200^{\circ} \mathrm{C}$ é ilustrada na Figura 7.

Comparando-se as Figuras 6 e 7 não é possível observar uma relação entre a fração volumétrica da austenita com as temperaturas de austenitização e a sua microdureza.

Nota-se, contudo, um aumento de dureza com o incremento na temperatura de austenitização. Existem pelo menos duas razões para esta tendência: uma é maior decomposição da cementita na austenita, aumentando o seu teor de carbono e resultando em uma martensita com maior dureza [I]. A outra é a redução da quantidade de ferrita proeutetóide (Figuras 2a-2b), uma vez que a austenita com maior teor de carbono apresenta maior temperablidade.

$\mathrm{Na}$ faixa de temperatura entre $800^{\circ} \mathrm{C}$ a $1.000^{\circ} \mathrm{C}$, a fração volumétrica de austenita retida permanece praticamente constante. Deve-se considerar, contudo, que os valores determinados nesta faixa de temperatura estão basicamente no limite de sensibilidade do método de quantificação utilizado $[19,20]$. Somente a partir de $1.100^{\circ} \mathrm{C}$, começa a haver um aumento da quantidade de austenita retida. A amostra temperada a partir de $1.200^{\circ} \mathrm{C} / 15 \mathrm{~min}$ resultou na máxima fração volumétrica de austenita retida.

\subsection{Determinação das Temperaturas Mi e Mf a partir da Análise do Perfil de Temperatura para a Austenitização a $900^{\circ} \mathrm{C}$}

A Figura 8a apresenta o perfil térmico e a sua derivada para a têmpera do aço a partir de $900^{\circ} \mathrm{C}$. Utilizou-se o método da derivação e, assim, obteve-se as temperaturas $M_{i}$ e $M_{f}$ pelas tangentes [2I] como se apresenta na Figura 8 b. $O$ exame da Figura 8 mostra uma mudança na inclinação da taxa de resfriamento entre $350^{\circ} \mathrm{C}$ e $260^{\circ} \mathrm{C}$ correspondente à formação da martensita, identificadas como temperaturas $M_{i}, 350^{\circ} \mathrm{C}$, e $M_{f}, 260^{\circ} \mathrm{C}$. Além disto, a Figura $8 \mathrm{~b}$ indica uma taxa de resfriamento máxima da amostra de aproximadamente $140^{\circ} \mathrm{C} / \mathrm{s}$ entre $750^{\circ} \mathrm{C}$ e $525^{\circ} \mathrm{C}$. Na literatura [2I], a temperatura $M_{i}$, para aços de composição similar ao estudado, pode ser calculada por:

$$
\begin{aligned}
& M i=512-453(\% \mathrm{C})-71,5(\% \mathrm{C})(\% \mathrm{Mn})- \\
& 16,9(\% \mathrm{Ni})+15(\% \mathrm{Cr})-9,5(\% \mathrm{Mo})+ \\
& 217(\% \mathrm{C})^{2}-67,6(\% \mathrm{C})(\% \mathrm{Cr})
\end{aligned}
$$

A aplicação da Equação I retorna o valor de $M_{i}$ de $338^{\circ} \mathrm{C}$. Observa-se que ocorrem desvios entre as temperaturas $M_{i}$ e $M_{f,}$ calculadas e as obtidas experimentalmente. Estes se devem às pequenas diferenças de composição química não listada na equação, tamanho de grão austenítico, homogeneização da austenita, entre outros fatores. Contudo, os valores obtidos experimentalmente de $M_{i}$ e $M_{f}$ e o valor calculado de Mi sugerem que não deveria ser esperada a presença de austenita nas amostras analisadas. Neste sentido, o enriquecimento gradual em carbono da austenita

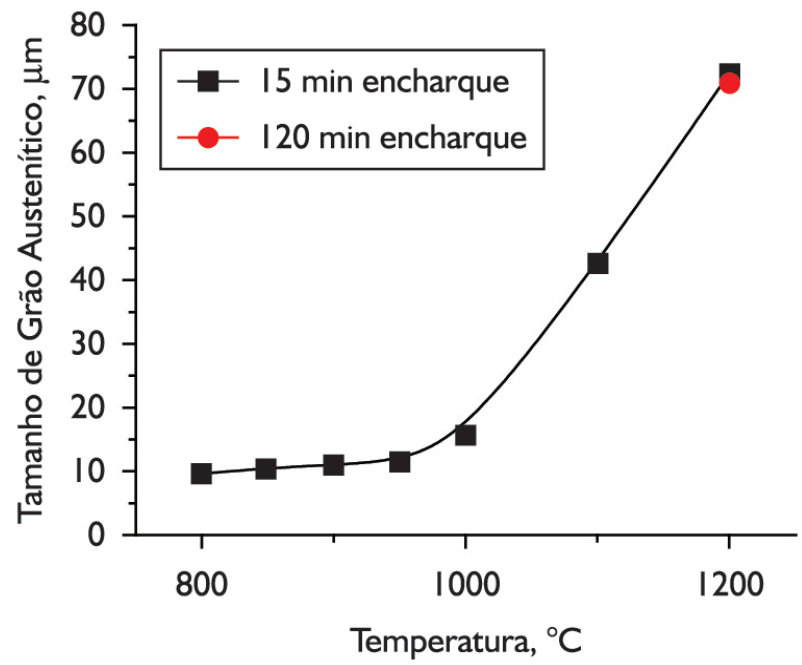

Figura 4. Tamanho médio do grão austenítico em função da temperatura de austenitização.

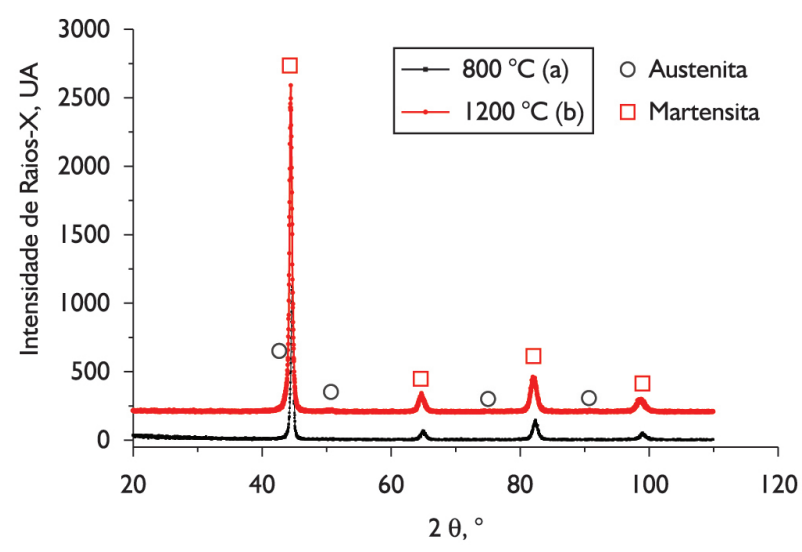

Figura 5. Difratogramas obtidos para as amostras austenitizadas a: (a) $800^{\circ} \mathrm{C}$; (b) $1.200^{\circ} \mathrm{C}$ durante 15 min e temperadas em água.

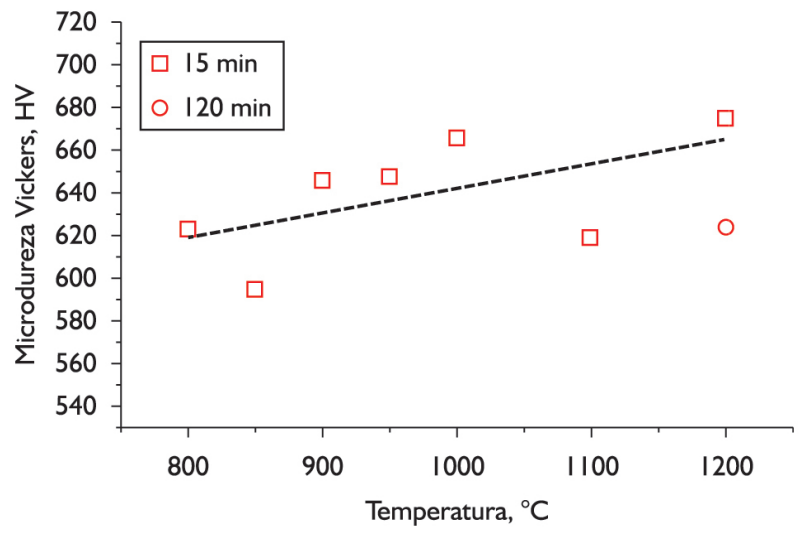

Figura 6. Microdureza Vickers em função da temperatura de austenitização e do tempo de encharque. 
em função do aumento da temperatura de austenitização não poderia justificar um aumento da fração de austenita retida, como ocorre nos aços de alto carbono ou nos aços ferramentas [6].

Os eventos iniciais de nucleação da martensita ocorrem no interior dos grãos em locais de concentração ou arranjo de discordâncias, que acontecem em diferentes intensidades. No entanto, a quantidade desses defeitos não é suficiente para transformar toda a austenita em martensita [12]. Os defeitos extras necessários para continuar a transformação advêm de um processo de autocatálise, pelo qual a formação das placas de martensita induz a nucleação de novos embriões que promovem a transformação adicional dentro destes grãos e fomentariam o crescimento de unidades de martensita a partir de contornos de grão, fazendo com que a nucleação em um grão ocorra em zig-zag e, assim, por diante, o que resulta em uma região de grão parcialmente transformada.

As regiões produzidas por estes eventos são delimitados por contornos de grão da austenita. Normalmente, a reação

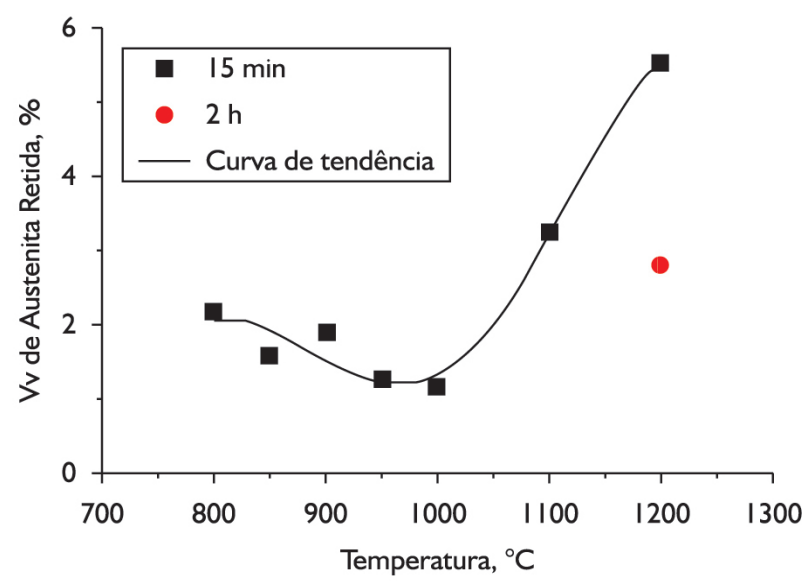

Figura 7. Variação da fração volumétrica de austenita retida, $\mathrm{Vv}$, com a temperatura de austenitização.

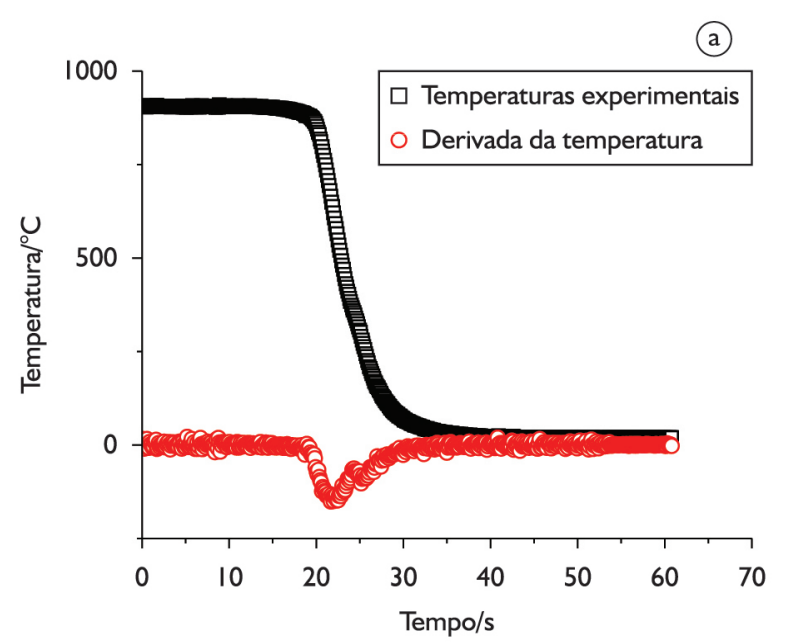

martensitica prossegue por nucleação de novas unidades e não pelo crescimento de unidades existentes. Além disso, as placas atingem o seu tamanho final quase instantaneamente, levando à conclusão que nucleação de martensita controla a cinética de transformação [17]. A nucleação da martensita nova em grãos não transformados leva novas regiões a se transformarem. Uma vez que um evento de transformação começa de forma localizada, refletindo a nucleação inicial de martensita, a formação de novas unidades é limitada pelas regiões ainda não transformadas [ $1 \mathrm{I}-13]$.

Vários estudos $[9,12,16-18]$ relataram que em sistemas ferrosos o tamanho de grão austenítico afeta a temperatura $M_{i}$ pela redução da energia necessária para o cisalhamento se completar durante a transformação em função da eliminação de imperfeições na rede, devido à maior temperatura de austenitização. Da mesma forma, a nucleação da martensita pode ser impulsionada por um aumento nos aglomerados de lacunas, originando falhas no grão da austenita, devido a temperaturas de austenitização mais baixas [9]. Portanto, a temperatura $M_{i}$ deve aumentar com o aumento da temperatura de austenitização.

Quando o aço é temperado a partir de temperaturas mais baixas, os grãos e subgrãos da austenita são muito pequenos e a composição química é heterogênea. Existe, assim, um grande número de falhas cristalinas e segregações na microestrutura, favorecendo nucelação da martensita. Acredita-se que esta condição prevaleça para amostras austenitizadas até $1.000^{\circ} \mathrm{C}$, quando a variação no tamanho de grão austenítico é pequena (Figura 4). Para uma temperatura de austenitização mais alta, ocorre o crescimento de grão e coalescimento dos sub-grãos da austenita, decrescendo o número de falhas cristalinas. Os núcleos de martensita são formados inicialmente em microrregiões, nas quais a temperatura $M_{i}$ aumentou, e crescem como placas ou agulhas finas [17], (Figuras 2 e 3). Quando a temperatura de austenitização é muito alta, o grande número de falhas cristalinas da austenita diminuie consideravelmente, tornando

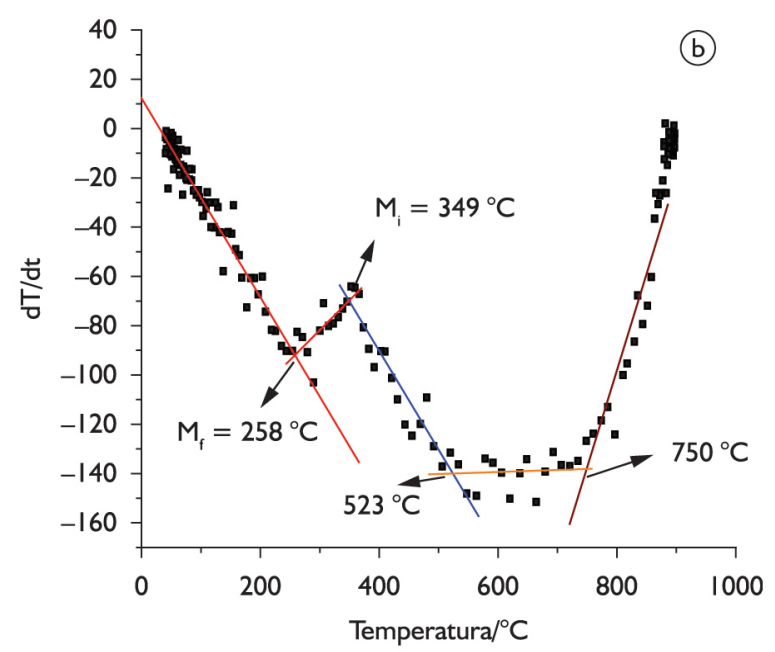

Figura 8. (a) Perfil de temperatura durante têmpera em água a partir de $900^{\circ} \mathrm{C}$ e encharque por 15 min; e (b) Derivada da temperatura em relação ao tempo em função da temperatura. 
a nucleação da martensita mais difícil, resultando em uma maior fração de austenita retida. Então a transformação martensítica acontece pelo crescimento dos núcleos iniciais, que se desenvolvem como placas e feixes de ripas (Figuras 2a, 2b e 3b). Outro importante fator a se considerar é o tamanho mínimo do grão austenítico para o qual a transformação martensítica não acontece. Segundo Kashchenco e Chashchina [22], este tamanho se situa em torno de I $\mu \mathrm{m}$. Nesse caso, se a austenita residual possui dimensões próximas deste valor, ela se tornaria estável.

Em resumo, existem dois mecanismos principais que devem ser considerados na interpretação dos resultados deste trabalho: (i) Não existe um obstáculo acentuado para o crescimento de núcleos da martensita através da perda de mobilidade da interface austenita-martensita ou um aumento de resistência mecânica na matriz austenítica; (ii) existe um impedimento para a nucleação da martensita. Como não existe a atuação do primeiro, resta o exercício do segundo. Assim, como a autocatálise decresce acentuadamente com - aumento do tamanho de grão da austenita, a nucleação é então reduzida. Isto se evidencia por que as placas de martensita são grandes para os grãos maiores e um menor número delas é nucleado, o que leva a uma menor fração volumétrica de martensita [13]. Tais considerações são reforçadas pelos resultados de Van Bohemen e Siestma [23], quando consideram em seu modelo que uma acomodação na austenita das tensões provocadas pela deformação plana invariante é a etapa crítica na formação de martensita atérmica. $\mathrm{Na}$ austenita de granulação grossa, esta acomodação acontece com maior facilidade devido à menor área de contornos de grãos e menor concentração de defeitos cristalinos, e, portanto, menor número de sítios de nucleação, reduzindo a componente de autocatálise. Uma evidência desse menor nível de tensões residuais é a menor intensidade do ataque químico na amostra ilustrada na Figura 3b. No caso da amostra austenitizada a $800^{\circ} \mathrm{C}$ (Figura 3a) os grãos do aço temperado são removidos pelo processo corrosivo da ação do reativo, auxiliado pelas tensões internas resultantes da têmpera, uma vez que o aço não foi revenido.

\section{CONCLUSÕES}

- Foi comprovado o aumento do tamanho de grão com o aumento da temperatura de austenitização, incluindo o crescimento anormal. Este acontece a partir de $1.100^{\circ} \mathrm{C}$;

- Observou-se o aumento da quantidade de austenita retida com o aumento da temperatura de austenitização para temperaturas superiores a $1.000^{\circ} \mathrm{C}$;

- Determinou-se experimentalmente, para o aço ABNT 5135 austenitizado a $900^{\circ} \mathrm{C}$, temperaturas $M_{i}$ e $M_{f}$, $349^{\circ} \mathrm{C}$ e $258^{\circ} \mathrm{C}$, respectivamente. $O$ valor de $M_{i}$ foi similar, embora um pouco superior, ao determinado com a equação empírica de Andrews;

- Entre as hipóteses discutidas que justificariam o aumento da fração volumétrica de austenita retida em função do crescimento acentuado do grão da austenita está a redução da autocatálise com o aumento do tamanho de grão da austenita.

\section{REFERÊNCIAS}

I Krauss G. Martensite in steel: strength and structure. Materials Science and Engineering A. 1999;273-275:40-57. http://dx.doi.org/10.1016/S092I-5093(99)00288-9.

2 Totten GE. Steel heat treatment - metallurgy and technologies. New York: CRC Taylor \& Francis; 2007. Chapter 6. p. 384-390.

3 Guimarães JRC. Conceituação, cinética e morfologia da transformação martensítica em aços. Revista Latinoamericana de Metalurgia e Materiales. 198I;I(I):3-9.

4 Lai GY, Wood WE, Clark RA, Zackay VF, Parker ER. The effect of austenitizing temperature on the microstructure and mechanical properties of as-quenched 4340 steel. Metallurgical Transactions. 1974;5(7): 1663-1670. http:// dx.doi.org/I0.1007/BF02646340.

5 Mohanty GO. On the stabilization of retained austenite: mechanism and kinetics. Materials Science and Engineering. 1995;32(3):267-278. http://dx.doi.org/10.1016/0921-5107(95)03017-4.

6 Matlock DK, Alogab KA, Richards MD, Speer JG. Surface processing to improve the fatigue resistance of advanced bar steels for automotive applications. Materials Research. 2005;8(4):453-459. http://dx.doi.org/I0.1590/SI5I614392005000400017.

7 Lee S-J, Lee Y-K. Effect of austenite grain size on martensitic transformation of a low alloy steel. Materials Science Forum. 2005;475-479:3 I69-3 I72. http://dx.doi.org/I0.4028/www.scientific.net/MSF.475-479.3169.

8 Yang H-S, Bhadeshia HKDH. Austenite grain size and the martensite-start temperature. Scripta Materialia. 2008;60(7):493-495. http://dx.doi.org/10.1016/j.scriptamat.2008.1I.043.

9 García-Junceda A, Capdevila C, Caballero FG, Garcia de Andrés C. Dependence of martensite start temperature on fine austenite grain size. Scripta Materialia. 2008;58(2):I34-137. http://dx.doi.org/10.1016/j.scriptamat.2007.09.017. 
10 Guimarães JRC, Rios PR. Martensite start temperature and the austenite grain-size. Journal of Materials Science. 20 I0;45(4): I074-I077. http://dx.doi.org/I0. I007/s I0853-009-4044-0.

II Guimarães JRC. Athermal martensite: Genesis of microstructure and transformations curves. Materials Science and Engineering A. 2008;476(I-2): I06-I I I. http://dx.doi.org/10.1016/j.msea.2007.04.068.

12 Bhadeshia HKDH, Christian JW. Bainite in steels. Metallurgical Transactions. A, Physical Metallurgy and Materials Science. 1990;2I(3):767-797. http://dx.doi.org/I0.1007/BF0265656I.

13 Cohen M. Martensitic nucleation - revisited. Materials Transactions, JIM. 1992;33(3): I78- 183.

14 Fisher JG. Application of nucleation theory to isothermal martensite. Acta Metallurgica. 1953; ( (I):32-35. http:// dx.doi.org/10.1016/0001-6160(53)90007-8.

I5 Lee S-J, van Tyne CJ. A kinetics model for martensite transformation in plain carbon and low-alloyed steels. Metallurgical and Materials Transactions. A, Physical Metallurgy and Materials Science. 2012;43(2):422-427. http:// dx.doi.org/I0.1007/s I I66I-0I I-0872-z.

16 Liu Y-J, Li Y-M, Huang B-Y. Influence of austenitizing temperature on apparent morphologies as-quenched microstructure of steels. Journal Central South University of Technology. 2006;13(2):I22-129. http://dx.doi. org/I0.1007/s I I77I-006-0|42-I.

17 Guimarães JRC, Rios PR. Unified description of martensite microstructure and kinetics. Journal of Materials Science. 2009;44(4):998-1005. http://dx.doi.org//0.1007/s 10853-008-32/8-5.

18 Ajus C, Tavares SSM, Silva MR, Corte RRA. Magnetic properties and retained austenite quantification in SAE 4340 steel. Revista Materia. 2009;14(3):993-999. http://dx.doi.org/I0.1590/SI5I7-707620090003000 I I.

19 Rodrigues TFM, Viana VDC, Modenesi PJ, Santos DB. Quantificação de austenita por meio da difração de raios-X em um aço inoxidável supermatensítico. In: Associação Brasileira de Metalurgia, Materiais e Mineração. Anais do $66^{\circ}$ Congresso da ABM; 20I I; São Paulo, Brasil. São Paulo: ABM; 20I I. p. I780-I79I.

20 Bernal C, Couto AB, Breviglieri ST, Cavalheiro ÉTG. Influência de alguns parâmetros experimentais nos resultados de análises calorimétricas diferenciais. Quimica Nova. 2002;25(5):849-855. http://dx.doi.org/10.1590/S0 I0040422002000500023.

2I Andrews KW. Empirical formulae for the calculation of some transformation temperatures. Journal of the Iron and Steel Institute. 1965;203:721-727.

22 Kashchenco MP, Chaschina VG. Critical grain size in the $\gamma \rightarrow \alpha$ martensite transformation. Thermodynamic analysis with regard to spatial scales characteristic of martensite nucleation. Physical Mesomechanics. 2010;13(3-4):189-194. http://dx.doi.org/10.1016/j.physme.2010.07.012.

23 Van Bohemen SMC, Sietsma J. Martensite formation in partially and fully austenitic plain carbon steels. Metallurgical and Materials Transactions. A, Physical Metallurgy and Materials Science. 2009;40(5): 1059-I068. http://dx.doi. org/| 0.1007/s I |66I-009-9796-2.

Recebido em: 8 Nov. 2013

Aceito em: 19 Jan. 2015 